\title{
(In)visibilidades e empoderamento das encenadoras no teatro brasileiro ${ }^{1}$
}

(In)visibilities and empowerment of women directors in the Brazilian Theater

Letícia Mendes de Oliveira ${ }^{2}$ 


\section{Resumo}

Este texto propõe uma reflexão e uma defesa acerca do papel da encenadora brasileira no século XX e XXI e da necessidade urgente de inseri-la na história do teatro. Aborda questões sobre o feminismo no teatro, problematiza as visões de encenação e analisa brevemente a trajetória das seguintes diretoras brasileiras: Bibi Ferreira, Dulcina de Morais, Henriette Morrineau, Lúcia Coelho, Bia Lessa, Maria Thais, Daniela Thomas, Cibele Forjaz e Christiane Jatahy. O objetivo é discutir como essas diretoras assumiram, para além da função da encenação, diversas atividades tais como atuação, gestão, pesquisa, direção visual, e sobretudo a tarefa de construção de uma poética da encenação brasileira.

Palavras-chave: Diretoras brasileiras; mulheres de teatro; encenação feminista; in(visibilidade)

\section{Abstract}

This text proposes a reflection and a defense about the role of the Brazilian director in the XX and XXI century and the urgent need to insert it in the history of theater. She addresses issues about feminism in theater, problematizes the visions of staging, and briefly analyzes the trajectory of the following Brazilian directors: Bibi Ferreira, Dulcina de Morais, Henriette Morrineau, Lúcia Coelho, Bia Lessa, Maria Thais, Daniela Thomas, Cibele Forjaz and Christiane Jatahy. The objective is to discuss how these directors have assumed, besides the role of staging, various activities such as acting, management, research, visual direction, and above all the task of constructing a poetics of Brazilian staging.

Keywords: Brazilian directors; theater women; feminist staging; in(visibility). 


\section{Olhares femininos e a encenação}

Há algum tempo, o questionamento sobre o (in)visibilidade e o apagamento das diretoras na história do teatro brasileiro vinha nos incomodando como artistas da cena. Nós, como mulheres, diretoras e pesquisadoras, deparamo-nos com as poucas pesquisas historiográficas e teóricas dedicadas à memória e à reflexão das encenadoras que construíram caminhos estéticos e políticos para as artistas do presente. Nomes contemporâneos como Cibele Forjaz, Christiane Jatahy, Daniela Thomas, Maria Thais, Bia Lessa, apenas para citar algumas, surgiam em nossas memórias profissionais como forças motrizes para alavancar esta investigação. Deste modo, várias questões nasciam quando pensávamos sobre o lugar das diretoras teatrais: quais estudos se dedicam a registrar a inscrição de suas histórias, origens e linguagens? Por que a história da encenação brasileira é marcada pela hegemonia masculina? Quais os percursos históricos e sociais que construíram a desigualdade entre diretores e diretoras? Diante dessas problemáticas, este artigo apresenta algumas contribuições para o rastreamento das diretoras brasileiras do século XX e XXI. Entretanto, ressaltamos que não temos a pretensão de realizar um rastreamento quantitativo das diretoras brasileiras neste texto, pois não conseguiremos aqui abranger a amplitude e profundidade do tema. Nosso foco refere-se ao reconhecimento da profissão da encenadora e ao levantamento de indagações e memórias teatrais para futuras investigações sobre a afirmação de um teatro feminista.

Como uma forma de lançar um primeiro olhar sobre esse campo de estudo, torna-se necessário destacar a visão feminista da filósofa Judith Butler, como uma maneira de argumentar sobre a relevância hoje da (in)visibilidade das mulheres em todos os setores da sociedade. Com a publicação em 1990, do livro Problemas de gênero, Butler questiona a distinção entre sexo e gênero, pois questiona a razão de o sujeito do feminismo ser apenas "as mulheres". Butler afirma que a chamada "heterossexualidade compulsória" imposta pelas instâncias reguladoras do poder, ou seja, pelo discurso hegemônico deveria ser substituída pela ideia de "construção variável da identidade" (Butler, 2010, p.23), e, desse modo, a autora estadunidense inclui as lésbicas e as transexuais neste painel. A filósofa defende um caráter de desconstrução de todas as identidades, enquanto as teorias feministas de um modo geral apresentam apenas a categoria "mulher" como o sujeito promotor de mudança e força política. Neste sentido, Butler coloca em xeque a categoria do feminino, e afirma que não se pode mais conceber esse sujeito "em termos estáveis ou permanentes" (Butler, 2010, p.18). A pensadora norte-americana acredita que, para se definir o sujeito, é necessário excluir e naturalizar, e, portanto, rejeita tal ideia, pois não concebe o caráter essencialista e fixo da noção de mulher. Se as primeiras teorias feministas ${ }^{3}$ postulavam uma distinção entre sexo e gênero, sendo que o primeiro corresponderia ao domínio anatômico e biológico e o segundo ao domínio sociocultural, Judith Butler afirma que tanto o sexo quanto o gênero são construídos socialmente, e, portanto, não é

\footnotetext{
${ }^{3}$ Sobre as teorias feministas reconhecidas da década de 1970, podemos citar o livro Man and woman, boy and girl, de 1974, de John Money e Anke Ehrhardt. A "identidade de gênero" apresenta uma distinção binária entre natural e social, ou seja, o sexo como uma base (biológica, invariável) sobre a qual as culturas se constroem, por meio da socialização e de diferentes concepções do que seja um homem ou uma mulher (Money, 1974)
} 
possível conceber o primeiro como natural. Dentro dessa visão, Butler (2010, p. 25) defende que:

\begin{abstract}
Se o caráter imutável do sexo é contestável, talvez o próprio construto chamado ‘sexo' seja tão culturalmente construído quanto o gênero; a rigor, talvez o sexo sempre tenha sido o gênero, de tal forma que a distinção entre sexo e gênero revela-se absolutamente nenhuma. Se o sexo é, ele próprio, uma categoria tomada em seu gênero, não faz sentido definir o gênero como a interpretação cultural do sexo.
\end{abstract}

Participando dessa visão de desconstrução da identidade feminina como naturalizada, nosso intuito é colaborar com as discussões atuais de visibilidade da mulher na arte, que busque um olhar horizontal nas relações de gênero. O objetivo é refletir a respeito do fenômeno de apagamento da mulher como diretora, que se constitui como um papel de comando artístico, e não deve ser "naturalizado" como masculino. É necessário dessacralizar uma tendência redutora e preconceituosa, imposta à artista, de que as funções de autoridade, técnica e coordenação no teatro não são destinadas à mulher. Portanto, é urgente atribuir visibilidade não somente às artistas contemporâneas, que ainda vivenciam dificuldades e preconceitos em suas funções, mas rastrear na história outras tantas diretoras precursoras do teatro moderno, como Bibi Ferreira, Dulcina de Morais, Henriette Morrineau, entre tantas mulheres, que alimentaram uma visão feminista teatral, ainda que este termo não fosse utilizado na primeira metade do século XX. Expostos os questionamentos sobre a (in)visibilidade da mulher a partir da teoria feminista de Judith Butler, e almejando o desejo de legitimação e inscrição das encenadoras, analisaremos adiante de modo crítico alguns pensamentos recorrentes sobre a direção e seu papel na história mundial, para confrontarmos com o lugar das mulheres diante desse panorama teatral.

\title{
Visões de direção e encenação teatral
}

Uma das principais e tradicionais ideias de encenação refere-se ao ato de pôr em cena um texto de teatro. Ideia essa que se mostrou insuficiente ao longo do século XX para abarcar a diversidade das linguagens cênicas em ampla reverberação na modernidade, tais como a Performance Art, o teatro-dança e o teatro de imagens, por exemplo, pois os artistas cênicos passaram a considerar o texto e a cena como fronteiras permeáveis de criação e não mais signos teatrais hierárquicos. Dentro desse contexto, mais precisamente na virada do século XIX para o XX, a noção de encenação apresentava ao mesmo tempo a ideia geracional de unificar e criar uma linguagem própria para os diversos elementos da cena, tais como cenografia, música, luz, texto e atuação, tendência como uma maneira de afirmação da categoria da direção. O teórico francês Jean-Jacques Roubine analisa o papel da direção dentro deste contexto e acredita que a direção apresenta uma visão específica de linguagem e um ponto de vista em relação ao espectador:

A direção não é mais (ou não é mais apenas) a arte de fazer com que um texto admirável (que é preciso admirar) emita coloridos reflexos, como uma pedra preciosa; mas é a arte de colocar esse texto numa determinada perspectiva; dizer a respeito 
dele algo que ele não diz, pelo menos explicitamente; de expô-lo não mais apenas à admiração, mas também à reflexão do espectador. (Roubine, 1998, p.41)

Convencionou-se dizer que o diretor ${ }^{4}$ buscava criar um espaço de criação e uma visão singular para determinada montagem, criando um repertório ou uma assinatura, metáfora essa que afirmou a hegemonia e a convenção teatral de que os diretores deixariam marcas e inscrições na história. História essa marcada, em sua maioria, por diretores homens, também chamados de mestres, guias ou mentores, 0 que contribuiu para uma desigualdade entre diretoras e diretores.

Neste sentido, consideramos essencial um pequeno parênteses dentro da discussão do conceito de direção, para inscrever a presença (in)visível na história da encenação da diretora Cosima Wagner, mulher de Richard Wagner. Dona de uma trajetória de vida fascinante e turbulenta, Cosima Francesca Gaetana Wagner (1837-1930) demonstrava uma personalidade singular e libertária para os padrões sociais do período em que viveu: filha ilegítima do músico Franz Liszt, foi esposa do maestro Hans von Bülow, e depois foi amante e posteriormente esposa de Richard Wagner. Cosima Wagner, após o falecimento de Richard Wagner em 1883, assumiu a gerência dos festivais de Bayreuth ${ }^{5}$ (Alemanha), dos quais ela manteve-se como diretora até 1908, e, após esse período, seu filho Siegfried Wagner assumiu o cargo. Pela estrutura familiar da época, Cosima assumiu a tarefa de direção do teatro e da companhia de forma quase auto-imposta, porém não houve economia de energias para continuidade dos trabalhos de Wagner, fazendo com que seu legado pudesse perdurar na história teatral. Cosima foi conhecida como uma força motriz em todos os setores dos festivais, tanto nos investimentos comerciais, quanto nas contribuições no repertórios dos artistas, na politização das obras de Richard Wagner, nos estilos da apresentação e nas relações com vários setores da sociedade alemã. Considerada como uma "sacerdotisa do culto wagneriano", Cosima viveu quase cinquenta anos de trabalho, mantendo a imagem do grande diretor Richard Wagner, devido à capacidade de gerenciamento de seu legado. Resta nos indagar: por que sua importância foi apagada da história do teatro mundial? Se Cosima Wagner vivesse atualmente poderia desenvolver sua capacidade autoral de direção, de forma autônoma, sem estar à sombra de Richard Wagner? Cosima deve ser inscrita na história do teatro como uma diretora relevante? Acreditamos firmemente que sim.

De volta à discussão sobre encenação e pensando na abrangência da direção hoje, considera-se fundamental salientar que a fluidez dos dispositivos teatrais independe de um texto-base para a criação, pois encenar significa colocar em cena experiências, visões, linguagens e posturas políticas. neste sentido, destacamos as proximidades e diferenças sutis entre direção teatral e encenação. Segundo o teatrólogo francês Patrice Pavis, em A encenação contemporânea:

\footnotetext{
${ }^{4}$ Nos livros de referência sobre encenação teatral ocidental, encontramos em geral o uso da palavra "diretor", e quase nunca "diretora", o que demonstra um predomínio da voz masculina também nas traduções brasileiras.

${ }^{5}$ O Festival de Bayreuth foi fundado em 1876 por Richard Wagner, com o intuito de criar um espaço de artes cênicas, descentralizado dos centros urbanos, para apreciação e difusão de suas obras. O primeiro espetáculo, dirigido por Wagner, que estreou em 13 de agosto de 1876 no festival foi Rheingold. Hoje, Bayreuth é considerado como um dos festivais culturais mais importantes da Alemanha e do mundo, já que a espera pela aquisição de ingressos pode durar anos. Desde 2012, as encenações são transmitidas também por inúmeras salas de cinema da Alemanha e por canais pagos de televisão. Atualmente, a bisneta de Richard Wagner, a professora Katharina Wagner dirige o Festival de Bayreuth, que se mantém como fundação e teatro.
} 
A encenação é, assim, uma representação feita sob a perspectiva de um sistema de sentido, controlado por um encenador ou por um coletivo. É uma noção abstrata e teórica, não concreta e empírica. É a regulagem do teatro para as necessidades do palco e do público. A encenação coloca o teatro em prática, porém de acordo com um sistema implícito de organização de sentido. (Pavis, 2010, p.3)

Pavis demarca a função de encenação relacionada a uma noção que é abstrata e teórica, e pertence à construção de uma linguagem cênica, produz sentidos e visões para o espectador, em consonância a essa primeira ideia, o teórico afirma que a direção está conectada à prática do trabalho diário do processo de criação, que se estabelece durante os ensaios, especificamente entre o encenador e os atuantes. (Pavis, 2010, p.4). Diante desse quadro, consideramos que o trabalho da diretora teatral apresenta as duas instâncias de ação, que são correlatas e inseparáveis: a primeira refere-se à criação de uma poética, ou seja, uma visão sobre a construção estética e ética da cena; e a segunda trata da condução da montagem, e não apenas da atuação, mas inclusive, do diálogo compartilhado com outros criadores cênicos, funções como cenografia, direção visual e musical e preparação de voz e corpo.

Já o professor inglês Paul Heritage, em Diálogos no palco: 26 diretores falam sobre teatro, que é uma relevante contribuição para o público brasileiro para os estudos da encenação, pois apresenta a visão de diretores e diretoras brasileiras e estrangeiras $^{6}$, afirma de modo entusiasta sobre ação multifacetada do diretor, e que ele é ao mesmo tempo o artista mais invisível e visível da cena teatral. Possui uma posição de comando e de destaque, mas que sua hegemonia passa ser contestada no atualidade. Heritage comenta sobre as diversas funções da direção:

\begin{abstract}
Apesar desta atração magnética e da posição supostamente dominante que o diretor ocupa agora, ainda é um papel estranhamente indefinido e pleno de alterações, com um grande número de responsabilidades, que exige alguém que seja ao mesmo tempo artista, filósofo, ator, pedagogo, alcoviteiro, professor, linguista, parteiro, técnico e administrador. (Delgado, 1999, p.17)
\end{abstract}

A ideia de um profissional faz-tudo é um senso comum predominante dentro da arte da encenação. É curioso notar que, refletindo sobre a fala de Heritage que aborda a versatilidade na ação do diretor, nós selecionamos justamente aqui diretoras que se afirmaram no cenário brasileiro por terem desenvolvido suas carreiras em conexão com outras funções teatrais, correlatas à direção, como atrizes, empresárias, cenógrafas, cineastas e iluminadoras, o que demonstra o ecletismo profissional e inventivo dessas encenadoras, que marcam a capacidade de sobrevivência, a criatividade, a liderança de grupos, a reinvenção, o empoderamento feminino e a inovação artística das mulheres do teatro brasileiro.

Explicitadas as funções da direção e da encenação, a seguir, faremos uma breve retrospectiva das diretoras brasileiras, na qual optamos por nos basear em duas abordagens de análise, que formam o recorte deste texto: uma abordagem historiográfica e crítica, que rastreia os nomes de artistas que tiveram uma função de incentivar a

${ }^{6}$ Dos vinte e seis diretores, apenas três são mulheres, duas estrangeiras, a cubana radicada nos EUA, Maria Irene Fornes e francesa Ariane Mnouchkine, conhecida por seu trabalho no grupo Théâtre du Soleil, e uma brasileira, Bia Lessa, que abordaremos neste artigo. 
profissionalização da direção feminina e o empoderamento de suas ações na cultura e a segunda refere-se a uma abordagem estética e política, que discute a contribuição de suas linguagens e projetos artísticos para instauração de poéticas da encenação para a contemporaneidade.

\section{As pioneiras encenadoras brasileiras: a versatilidade das atrizes e empresárias}

Refletir sobre a história das diretoras brasileiras no início do século XX significa relembrar as conquistas e as dificuldades da mulher dentro sociedade brasileira da época. A participação feminina nas esferas intelectuais e artísticas eram raras e incipientes, pois às mulheres eram destinadas as tarefas domésticas e o cuidado com os filhos. Ascender socialmente exigia inseri-las no mercado de trabalho e proporcionar acesso à educação, e esse movimento se dá a partir de três grandes conquistas: o direito ao trabalho, educação e voto ${ }^{7}$.

Outros fatores que também impulsionaram a participação feminina no mercado de trabalho foram a crescente industrialização no Brasil e, em menor grau, a escassez de mão de obra devido à ida dos homens para as guerras. Sobre a historiografia das mulheres neste contexto, uma importante referência sobre o assunto, no qual nos baseamos, é o livro organizado pelas pesquisadoras Ana Lúcia Vieira de Andrade e Ana Maria de B. Carvalho, intitulado $A$ mulher e o teatro brasileiro do século $X X$, e apresenta um quadro minucioso de atrizes, dramaturgas, diretoras e agitadoras culturais, que contribuíram para a afirmação da cena brasileira moderna e contemporânea. Tal livro foi essencial para este estudo, primeiro pela necessidade de legitimar pesquisadoras femininas brasileiras, e, segundo, por rastrear artistas que contribuíram para o empoderamento da mulher no teatro no século XX. Observamos, no entanto, que enfocaremos aqui especificamente as reflexões relacionadas às ações das diretoras, tal como Bia Lessa, e artistas, que assumiram em alguns momentos de suas carreiras a função de direção. Sabe-se então que a presença feminina no teatro no Brasil ainda não estava totalmente estabelecida, e, por esse motivo, os primeiros relatos sobre a participação de mulheres na cena foram com o ofício de atriz e, ao mesmo tempo, de forma preconceituosa, como uma variante do universo da prostituição. A mulher era considerada de modo restrito e idealizado como a grande "estrela" das produções teatrais e até hoje este estigma ainda permanece na cultura brasileira, seja no teatro, seja na televisão. Já falar da ação da mulher em funções técnicas ou de coordenação e gerenciamento de coletivos era algo impensado ou inadequado para época.

Deste modo, a direção feminina também surge de modo tardio, e quando essa ação se torna visível, dá-se como uma variação das atividades de atriz, de empresárias e, não menos importante, de formadoras de opinião e de tendências do recente teatro moderno brasileiro. Inclusive, é relevante, neste sentido, evidenciar que o teatro no Brasil experimentava um momento singular, pois apresentava o paradigma peculiar histórico entre o teor amadorístico e comercial e, ao mesmo tempo, a tentativa de modernização, com respiros vanguardistas. Sobre esse aspecto, o teórico

${ }^{7}$ Segundo a pesquisadora Ana Lúcia Vieira de Andrade, o direito ao voto feminino se dá em 1932, com restrições, pois somente podiam votar as casadas, viúvas e solteiras com renda própria. $O$ voto livre e obrigatório acontece somente em 1946 (Andrade, 2008, p.16). 
teatral Edelcio Mostaço problematiza a questão da diferença entre o vanguardismo europeu e a história do teatro brasileiro moderno como um "assincronismo estrutural" (Mostaço, 2015, p.254). O pesquisador discute que a cena nacional não pode ser pautada inteiramente pelo contexto internacional, pois apresenta um forte passado escravocrata, amplas diferenças sociais territoriais e a necessidade de se buscar uma identidade própria. Ao mesmo tempo, Mostaço diz que é inegável não reconhecer as influências recebidas pelos movimentos estrangeiros no teatro brasileiro. Neste sentido, Mostaço elabora a seguinte explanação:

O país não era civilizado não porque a cena nacional se mostrasse "inculta", mas porque um tenebroso regime escravocrata andava de mãos dadas com um Estado ainda imperial, num momento em que toda a América já superara tais patamares "bárbaros". Por outro lado, as primeiras cogitações estéticas modernistas começam a ganhar consistência entre nós em meados da segunda década do século XX, num momento em que a Europa vivia estarrecida a Primeira Guerra. [...] As clivagens entre a cena internacional e a nossa podem ser dimensionadas na mesma medida em que a modernidade não conheceu, lá e aqui, o mesmo timing, por obra e graça das distintas configurações sociopolíticas, das diferenças estruturais existentes, dos pronunciados desníveis culturais entre norte e sul. (Mostaço, 2015, p.253-257)

De volta à discussão sobre a presença das mulheres na história teatral e considerando o contexto paradigmático do teatro moderno, compreende-se que o adiamento do papel da diretora no teatro ocorre concomitante a diversas transformações estéticas e sociais que o Brasil vivenciava na primeira metade do século XX. No entanto, buscando um diálogo com os ares da modernização, diversas atrizes empreendedoras brasileiras lutaram à frente de suas companhias para a efetivação do ofício, por direitos à classe e respeito de gênero, assim como Bibi Ferreira, Cacilda Becker, Dulcina de Moraes, Fernanda Montenegro. Inclusive a artista estrangeira francesa Henriette Morineau, que se juntou à causa das artistas brasileiras, e a incluímos em nossa reflexão, mesmo não sendo sua origem brasileira, pois devido à sua ação decisiva de profissionalização dos artistas, acreditamos que a atriz apresenta uma perspectiva identitária brasileira.

Revisitando outros autores sobre o teatro brasileiro em relação à ação das mulheres como diretoras-gestoras, Décio de Almeida Prado destaca a importância do papel de fomentadoras de Dulcina de Moraes e Henriette Morineau e as nomeou como "atrizes-encenadoras", expressão que nos chamou a atenção, por atribuir a ambas um lugar de criadoras da cena e não apenas como "ensaiadoras" ou empresárias. Deste modo, iremos explanar brevemente sobre algumas realizações dessas grandiosas atrizes e empresárias, que estreiam no teatro a partir de 1920, e tornam-se expressivas no meio teatral, a partir de 1940.

Como atriz integrante da companhia de Louis Jouvet, Henriette Morineau (19081990) participava de uma turnê pela América Latina, e decidiu, em 1942, por não prosseguir a viagem de retorno à França e ficar no Brasil, onde posteriormente fixou residência e contribuiu vastamente para o teatro carioca. Segundo Décio de Almeida Prado, Morineau, ao participar do elenco das peças dirigidas por Jouvet, tornou-se uma das figuras mais emblemáticas do teatro brasileiro do período da década de 
1940. Já familiarizada com o idioma português, Morineau apresenta uma significativa importância para a formação de grupos, ao criar, em 1946, Os Artistas Unidos, o que desencadeou fortes ímpetos de profissionalismo teatral e, também contribuiu, para apresentar ao público brasileiro, o texto $A$ street named desire, do americano Tennessee Williams, traduzido no período como Uma rua chamada pecado (Prado, 2008, p.42).

Filha da atriz cubana Conchita Bernard Vallina, Dulcina de Moraes (1908-1996), esposa de Odilon Azevedo, criou em 1934 a Companhia Dulcina-Odilon, e fez sua carreira como uma grande empresária e comediante de vaudevilles e comédias parisienses. Seu legado incluem a profissionalização de seu elenco, a abertura de temas femininos para o grande público, além das montagens de dramaturgos modernos estrangeiros como Bernard Shaw, Giraudoux, Somerset e García Lorca que a torna uma mulher de teatro reconhecida nos anos 1940, por sua vertente de renovação, intensa produtividade e rigor no fazer cênico.

A próxima artista que contribuiu decisivamente para a profissionalização das artistas nos anos 1940 e em todo século XX foi Bibi Ferreira. Atriz, empresária, diretora fervorosa dos grandes musicais, Abigail Izquierdo Ferreira (1922-) criou sua primeira companhia em 1944 com apenas vinte e dois anos, com o apoio do pai, Procópio Ferreira, a chamada Companhia de Comédias Bibi Ferreira, onde Henriette Morineau se juntou em 1945. Porém, a crítica sobre sua companhia recai devido a suas escolhas de repertório, que ainda acompanhava uma tendência comercial e tradicional de interpretação da época, apesar de sempre apresentar produções cenográficas impecáveis e cuidadosas. Anos mais tarde, em 1948, sua personalidade marcante aliada à maturidade conquistada, dirigiu Procópio Ferreira em Divórcio, pela companhia do pai. Esta peça a projetou como uma diretora respeitável devido a alguns fatores: primeiro, o desafio de dirigir seu pai em um drama, já que Procópio era uma comediante clássico, segundo, a tarefa de conduzir atores experientes (Alma Flora, Darci Cazarré, Palmerim Silva e Belmira de Almeida) na companhia do pai, e terceiro, por ser uma jovem mulher de vinte e seis anos, que buscava o reconhecimento de sua profissão. Com uma temporada lotada de seis meses no Teatro Serrado, Divórcio alcançou sucesso de público e a projetou como uma diretora, que a partir daí, montou textos de autores dramáticos modernos, dirigiu a Companhia Dramática do Serviço Nacional de Teatro, na década de 1950, até se especializar, definitivamente, até os dias atuais, com os musicais e as óperas, suas grandes paixões.

\section{Encenadoras Pedagogas}

Caminhando na história do teatro brasileiro da segunda metade do século XX, destacamos a importância de algumas diretoras, que apresentam uma característica relevante para a formação do artista cênico nacional: as chamadas encenadoras pedagogas. Devido ao caráter de brevidade de nossa exposição, optamos por abordar apenas três delas, o que não contempla outras tantas mulheres que se dedicaram e se dedicam hoje à esfera interdisciplinar entre teatro e educação. São elas: Myrian Muniz, Lúcia Coelho e Maria Thais. 
A atriz, diretora e professora Myrian Muniz (1931-2004) foi uma mulher fundamental no teatro brasileiro de vocação política das décadas de 1960 e 1970, vivenciando as experiências do Teatro de Arena, a censura, a ditadura, e o estabelecimento do Teatro Escola Macunaíma. Formou-se em 1962 na Escola de Arte Dramática (EAD/ USP), e logo já se destacou no teatro profissional como atriz cômica. Ainda como atriz realizou várias montagens do Teatro de Arena, tais como O Inspetor Geral, de Nikolai Gogol, em 1966, e Primeira Feira Paulista de Opinião, espetáculo-colagem de Augusto Boal, de 1968, que registra o tenso momento de conflitos entre as políticas de esquerda e direita no país. No mesmo ano, Muniz integrou o elenco de Marta Saré, com texto de Gianfrancesco Guarnieri e Edu Lobo. Em 1971, voltando como diretora de atores da Escola de Arte Dramática (EAD/USP) onde se formou, Muniz também assume ao mesmo tempo a montagem de Ralé, de Maximo Górki, um grupo de operários de São Bernardo dos Campos, e neste momento consolida sua poética, que alia uma criação pautada pelo trabalho cuidadoso e processual com a formação de atrizes e atores à uma postura política engajada em relação à sociedade. Em 1975, seguindo o ideal de uma formação coletiva e experimental, inaugurou o Teatro Escola Macunaíma, em São Paulo, e, no mesmo ano, dirigiu a cantora Elis Regina no show Falso Brilhante, que a projetou como uma renomada diretora profissional nos anos 1970. Ainda sobre a importância da Escola Macunaíma e ação pedagógica de Muniz, o pesquisador Marcelo Braga Carvalho (2011, p. 40) comenta:

O Macunaíma representou a concretização da atuação de Myrian como pedagoga. A partir de sua inauguração, ela possuía, de fato, um espaço reservado para essa atividade onde tinha autonomia para fazer escolhas pedagogicamente efetivas nos processos criativos que liderava e onde também podia fazer experimentos cênicos, o que não acontecia no teatro profissional, um dos motivos pelos quais, ela preferiu o ensino e dedicou tanto tempo da sua carreira aos seus alunos-atores.

Já a diretora de teatro de animação e teatro infanto-juvenil Lúcia Coelho (19342014) é um exemplo de mulher que se dedicou inteiramente à formação do público e à popularização das ações de acesso ao teatro. O seu início na direção se deu com o grupo Navegando, em 1978, com a montagem de Tá na hora, tá na hora, em que já apresentava uma pesquisa da linguagem circense e teatro de bonecos. Diretora de mais de quarenta peças entre os anos 1980 aos 2000 e vencedora de mais de 20 prêmios por criações dirigidas ao público infantil, tais como Moliére, Coca Cola de Teatro Jovem, Mambembe e CBTIJ, Coelho se manteve ativa até depois dos anos 2000 e foi responsável pela programação infantil do Teatro Poeira e dirigiu a Escola Fábrica de Espetáculos, que atendeu crianças e adolescentes de baixa renda, em São Paulo. Coelho, deste modo, legou para as futuras gerações de diretoras um fazer teatral pautado na criação coletiva, na artesania do teatro de formas animadas e no ofício de uma encenadora pedagoga com a missão de formação dos artistas brasileiros e do público jovem.

Dentro do panorama de mulheres relacionadas à formação de atores e de uma visão social de teatro, é inegável a contribuição na atualidade da diretora, pesquisadora, coreógrafa, preparadora corporal Maria Thais para uma noção expandida de encenação e pedagogia, consolidada na contemporaneidade. Professora da Univer- 
sidade de São Paulo e fundadora da Companhia de Teatro Balagan, Maria Thais Lima Santos (1960-) tem uma longa trajetória como diretora, pesquisadora e professora em São Paulo. Foi diretora do TUSP (Teatro da Universidade de São Paulo), entre 2007 e 2010 e, pela Companhia de Teatro Balagan, dirigiu: Recusa, de 2012, Prometheus, a tragédia do fogo, de 2011, Západ, a Tragédia do Poder, de 2006, Tauromaquia, de 2004, A Besta na Lua, de 2003, e Sacromaquia, de 2000. Colaborou entre os anos de 1999 e 2006 como diretora-pedagoga com a Moscow Theatre, pela Scholl of Dramatic Art, em Moscou e foi coreógrafa do espetáculo Ilíada, dirigido por Anatoli Vassiliev. Autora do livro Na Cena do Dr. Dapertutto: Poética e Pedagogia em V. E. Meierhold, de 2010, a diretora criou metodologias de trabalho inovadoras para a atuação, pois confrontou os procedimentos do encenador russo às práticas brasileiras como a capoeira, danças africanas e trabalhos corporais com a máscara neutra.

Sobre seu olhar como encenadora, Silvia Fernandes realiza uma crítica sensível do espetáculo Sacromaquia, ao evidenciar o intuito de Maria Thais em criar uma obra polifônica, através da metodologia do processo colaborativo, em voga entre os anos 1990 a 2000. Sacromaquia discutiu o enclausuramento feminino, com textos, imagens e histórias baseadas em Mariana de Alcoforado, Tereza d'Ávila e Juana Inês de la Cruz, apresentada em um espaço claustrofóbico, que se movimentava ao longo da peça. Silvia Fernandes analisa a peça:

A rebeldia física das mulheres, pautada em movimentos de capoeira e candomblé, e, ocasionalmente, na fala em dialetos africanos, compunha corporalmente elementos de uma cultura alterna, que expunha, no código gestual e textual, a relação ambígua das religiosas com seu corpo. Dessa forma, o trabalho das atrizes, feito de contenção e extravasamento, conseguia transformar a rebeldia latente do texto em ambivalência interpretativa. (Fernandes, 2010, p.218)

Nota-se que Maria Thais Lima apresentou, a partir de Sacromaquia, uma poética de encenação centrada na corporeidade brasileira, no engajamento dos olhares femininos e na retomada das memórias de mulheres incompreendidas na história. A encenação de Maria Thais Lima emerge em carne feminina e torna visível e latente um trabalho imagético, gestual e provocante, que são marcas de sua direção autoral. $\mathrm{Na}$ próxima seção, abordaremos outras diretoras do teatro contemporâneo brasileiro, contemporâneas de Maria Thais.

\section{As encenadoras contemporâneas: visualidades, hibridismos e experimentalismo}

Chegando aos ares dos anos 1980, Beatriz Ferreira Lessa (1958-) inaugura nos palcos brasileiros o teatro de imagens e uma estética de forte instabilização do espaço cênico, em paralelo com as experiências do encenador Gerald Thomas. Bia Lessa logo se destaca na direção com um caráter experimental e visual. Grande parte de seus trabalhos foram realizados no Teatro Sesc Tijuca, na década de 1980, e no Centro Cultural Banco do Brasil, nos anos 1990, no Rio de Janeiro, e trabalhou com várias atrizes experientes, tais como Guilia Gam, em Cena de Origem, de Haroldo de Campos, em 1989, Fernanda Torres, em Orlando, de Virgínia Woolf, e no mesmo ano, Luciana Braga e Carla Camuratti, em Cartas Portuguesas, em 1991. A prática de 
atuação de Bia Lessa busca uma autoralidade dos próprios fazedores, pois, para a diretora, cada peça exige uma abordagem, da mesma forma que cada indivíduo exige um olhar específico. Sobre a atuação, Lessa afirma:

Quem é artista tem que ser dono, não pode ser empregado, você não é empregado de ninguém; você não tem que descobrir o que é que aquele texto vai dizer; você é quem vai dizer como ele é que você vai fazer aquele texto. (Entrevista com Bia Lessa. Delgado, 1999, p.79)

Bia Lessa é diretora de grandes espetáculos, desfiles de moda, exposições de artes visuais, cinema, óperas e eventos musicais. Sua versatilidade aliada à ousadia plástica, ao uso de grandes espaços aéreos, linhas e vazios, fazem da diretora uma artista da desconstrução e do trânsito entre as fronteiras das diversas linguagens artísticas. Com Ensaio no 3 - Ideias e Repetições - um musical de Gestos, montagem cênica concebida em 1986, a partir de textos de Jorge Luis Borges, Julio Cortázar e Lygia Bojunga, Lessa é premiada (a primeira mulher a ganhar essa categoria) com o Prêmio Molière, de melhor direção e inicia sua trajetória transcriação de grandes textos dramáticos e literários para os palcos. Atualmente, Lessa continua sua trajetória experimental no teatro brasileiro, e, em 2017, dirige a montagem de Grandes Sertões Veredas, de Guimarães Rosa, e confirma sua vocação para a construção de grandes ambientes cenográficos, ao instalar uma grande estrutura metálica no palco e, ao mesmo tempo, inserir espectadores dentro do espaço de atuação. Com uma adaptação cuidadosa e a utilização de narrativas em cena, os atores e atrizes usam figurinos contemporâneos e assumem apenas suas corporeidades e voz para criar o universo roseano para cena. Lessa recebe por esta peça o Prêmio APCA (Associação Paulista de Críticos de Artes), de melhor direção, no mesmo ano, mantendo-se como uma encenadora inventiva e vanguardista do teatro brasileiro.

Outra grande encenadora que investe no experimentalismo visual do teatro é Daniela Thomas (1959-). Nascida Daniela Gontijo Alves Pinto, filha do cartunista Ziraldo e irmã do compositor Antonio Pinto, seu primeiro trabalho teatral foi a cenografia para All Strange Away, de Samuel Beckett no Teatro La MaMa (Nova York/EUA), em 1983. Cenógrafa, figurinista, iluminadora, diretora, Daniela foi responsável por várias cenografias do teatro nacional, e foi grande parceira das encenações de Gerald Thomas, com quem realizou experimentações monumentais de telões, transparências, cenários mimimalistas e maquinarias o palco. Destacando-se também como cineasta e roteirista, Thomas dirigiu em 1994, conjuntamente com Walter Salles, o filme Terra Estrangeira, que a projetou como uma grande cineasta nacional. Em 2007, novamente com Walter Salles, dirigiu o filme Linha de Passe, e conquistou o prêmio de melhor atriz no Festival de Cannes para a atriz Sandra Corveloni. Em 2016, demonstrando sua versatilidade como diretora de grandes shows, dirigiu junto com Fernando Meirelles e Andrucha Waddington a Cerimônia de Abertura dos Jogos Olímpicos de Verão, no Rio de Janeiro.

Sobre sua obra, a professora Sílvia Fernandes faz uma minuciosa análise de uma das peças, que Thomas dirigiu e que a projetou como uma grande encenadora brasileira: Gaivota, de 1998. No elenco, atrizes e atores com uma ampla experiência: Antônio Abujamra, Celso Frateschi, Fernanda Montenegro, Fernanda Torres 
e Matheus Nachtergaele apresentavam os personagens solitários tchekhovianos ao lado da presença real de uma gaivota empalhada em cena, com o intuito de discutir o presente e o passado do própria teatro. Sílvia Fernandes faz uma análise da encenação de Thomas, e confronta o retrato simbólico da gaivota à discussão ampliada da própria profissão do teatro:

Esta polifonia de vozes dissonantes encontrou sua melhor tradução cênica na concepção de Daniela Thomas, autora, encenadora, cenógrafa e artesã deste trabalho. Apesar de extirpar nada menos que quatro personagens e outras tantas falas do texto, conseguiu ampliar a ideia central da gaivota tchekhoviana. Sem deixar de refletir sobre o conflito existencial do artista de teatro, priorizou a discussão dos teatros, escolhendo, para seu seu elenco, legítimos representantes dos teatros brasileiros, atores que carregam na simples presença de uma linguagem, uma linha de trabalho, uma história inconfundível e, mais que isso, uma inalienável opção profissional. (Fernandes, 2009, p.15)

Em 2018, dirigiu o filme $O$ banquete, com Drica Moraes e Mariana Lima, e realiza um trabalho minucioso de atuação, que representa o momento político conflituoso de retomada da democracia no fim década de 1980, no Brasil. O filme que apresenta um ambiente marcadamente teatral pela cenografia e atuação latente de atrizes e atores com longa experiência cênica, conta a narrativa de uma jornalista que descobre segredos escusos sobre o presidente do país. O hibridismo entre cinema e teatro é uma marca constante na poética de Daniela Thomas como encenadora.

Falando de hibridismo, uma encenadora que vem trabalhando na fronteira entre a luz e a direção é a paulista Cibele Forjaz. Formada em direção pela Escola de Comunicação e Artes da USP, Cibele Forjaz Simões (1966-) é diretora e iluminadora integrada às mais inquietas correntes de pesquisas cênicas coletivas e colaborativas a partir da década 1980 e mais intensamente na década 1990. Sua formação passa pelo Centro de Pesquisa Teatral (CPT), de Antunes Filho e pelo curso de Direção Teatral da Escola de Comunicações e Artes da Universidade de São Paulo (ECA/USP), onde atualmente é professora de iluminação. Seus primeiros trabalhos são realizados com o grupo Barca de Dionisos, do qual é uma das fundadoras, juntamente com o diretor William Pereira. Trabalhando como iluminadora do Teatro Oficina, sua projeção como encenadora acontece com o espetáculo $A$ Paixão Segundo $G H$, inspirado na obra de Clarice Lispector, levando Marilena Ansaldi a um brilhante desempenho, em 1989. No ano seguinte, a diretora encena $O$ Lamento de Ariadne, de Beatriz Azevedo, ainda pelo grupo Barca de Dionisos.

Em 1991, Forjaz dirige Woyzeck, o brasileiro, de Georg Büchner, com dramaturgia de Fernando Bonassi e elenco formado por Matheus Nachtergaele, Marcélia Cartaxo, Niltinho Bicudo, entre outros atuantes. Numa grande instalação cenográfica composta por Marcos Pedroso, com a presença feminina e essencial na equipe de criação visual da cenógrafa Fátima Costa de Lima, (atualmente professora de Espaço Teatral do Curso de Teatro da UDESC em Florianópolis/SC), a peça aconteceu em um estacionamento na Rua Augusta em São Paulo, investindo em experimentos cênicos com espaços cênicos não-convencionais, procedimento esse recorrente da poética de encenação de Forjaz. No mesmo ano, encena Florbela, texto que Alcides Nogueira extrai da obra poética de Florbela Espanca, destacando a atriz Denise Del Vecchio no 
papel principal. Em 1994, cria uma ousada versão para Álbum de Família, de Nelson Rodrigues, com o Núcleo de Pesquisa Teatral, grupo de São José dos Campos; voltando em 1997, com o mesmo elenco, à criação de Salve Manoel, Bandeira do Brasil!, baseada em poemas do escritor modernista. Ainda com esse conjunto encena, em 1998, A Vida de Galileu, de Bertolt Brecht, com Renato Borghi como protagonista. Sua versão para Toda Nudez Será Castigada, de Nelson Rodrigues, forma um novo grupo, a Companhia Livre, com a atriz Leona Cavalli, em 2000. No mesmo ano, encena Um Bonde Chamado Desejo, de Tennessee Williams, consolidando a atriz Leona Cavalli entre as grandes jovens intérpretes dos últimos anos. Analisando a encenação de Forjaz de Um Bonde Chamado Desejo, o crítico Alberto Guzik observa:

Cibele Forjaz e a cenógrafa e figurinista Simone Mina criaram no centro do amplo palco do Sesc Belenzinho uma espécie de gaiola delimitada por fitas elásticas brancas, e ali situam o drama. O espetáculo apresenta imagens grandiosas e belas, fluente, permeado de um clima de sonho e melancolia acentuado pela música de Cacá Machado e pela luz de Alessandra Domingues, que dialoga com o realismo, mas não se limita a ele. [...] Um Bonde Chamado Desejo confirma o importante papel que a diretora Cibele Forjaz está desempenhando no teatro brasileiro contemporâneo". (Guzik, 2002)

Nos últimos anos, Cibele Forjaz vem dirigindo incansavelmente como diretora convidada de grupo paulistas contemporâneos. Esteve à frente da direção de $O$ Idiota, de 2010, adaptação teatral da obra de Dostoievski, que dirigiu para um grupo de atores, a Mundana Companhia, advindos de diversas outras companhias teatrais: Teatro Oficina, Teatro da Vertigem, Cia. Livre e Cia. da Mentira, de São Paulo. A ousada montagem que levou dois anos para ser finalizada e durava quase sete horas de apresentação foi um experimento incansável de ocupação e comunhão com o espectador. Em 2018, Cibele Forjaz dirige a peça Dostoievski-Trip, novamente com a Mundana Companhia, e retoma o universo do escritor russo aliada à crise brasileira, num clima alucinógeno de imagens desconexas. Forjaz finca na cena brasileira contemporânea sua força autoral, que une a encenadora à iluminadora, uma dramaturgia calcada nas fronteiras entre real e imaginário, uma postura engajada política, a ousadia visual, o trabalho intenso com a atuação e o experimentalismo dos espaços não-convencionais.

A última encenadora sobre quem iremos refletir é Christiane Jatahy (1968-). Autora, diretora de teatro e cineasta carioca, seus trabalhos se iniciam em 2003 e dialogam com distintos meios artísticos diversos e relações intermidiáticas na composição da cena. No teatro, Jatahy escreveu e dirigiu peças que transitam entre as fronteiras da realidade e da ficção, e que fazem uso de filmagens projetadas gravadas e ao vivo, tais como a obra Conjugado, de 2004, que se constitui como uma performance vídeo-instalação, baseada em entrevistas sobre a solidão no contexto das cidades urbanas. A ação dessa performance acontecia dentro de um cubo vista pelo público através de persianas. Já $A$ Falta que nos move ou Todas as histórias são ficção, de 2005 a 2012, tornou-se peça e filme, e narra fatos sobre a geração "coca-cola", criada após o período da ditadura brasileira; e Corte Seco, de 2009, é uma peça mosaico, montada com um filme ao vivo na presença do público.

Em 2011, Jatahy estreou Julia, adaptação da obra Senhorita Julia, de August Strindberg. Por esse trabalho ganhou o Prêmio Shell de Melhor Direção em 2013. Em 
2012, foi a diretora artística do projeto Rio Occupation London, residência com 30 artistas de diferentes áreas. Em 2013, desenvolveu o projeto de instalação audiovisual e documentário Utopia.doc em Paris, Frankfurt e São Paulo. Já a montagem de E se elas fossem para Moscou?, de 2014, foi criada a partir da obra As três irmãs, de Anton Tchekhov, e foi apresentada em dois espaços diferentes como uma peça e um filme, ao mesmo tempo. No teatro, o filme é captado, editado, enquanto isso, é projetado em outro espaço, em tempo real, numa sala de cinema. Jatahy, deste modo, incorpora em sua encenação uma poética do cotidiano, com histórias comuns, concomitante ao uso de tecnologias audiovisuais, transitando entre o sensível e o midiático, características do hibridismo do teatro contemporâneo brasileiro. Neste sentido, Jatahy comenta sobre seu próprio processo criativo, em entrevista concedida ao pesquisador José da Costa (2015, p. 213):

\footnotetext{
No meu processo de trabalho, tem um aspecto muito importante, que se associa à forma. A minha criação se dá primeiramente na relação espaço $\times$ conteúdo. Eu sempre reflito, no primeiro momento sobre como o conteúdo vai estar dentro de um espaço determinado. Há um aspecto bastante formal nisso. Mas esse aspecto formal é completamente perfurado por uma proximidade com a vida que se dá tanto no encontro com os atores e no que eles podem aportar ao trabalho, como também no que proponho como risco, como acaso, nos dispositivos que crio para que essa pré-estrutura seja perfurada tanto no processo de criação como no próprio momento em que o espectador está assistindo, portanto, no que a gente pode chamar de resultado.
}

A encenação de Christiane Jatahy apresenta-se como um panorama ambíguo de linguagens entre o ficcional e o real, entre a artesania e o tecnológico, entre o teatro e a vida. Para Jatahy (2010), "as fronteiras são zonas de instabilidade, de risco, onde um território avança sobre o outro ultrapassando linhas invisíveis". Territórios esses que geram uma pluralidade de olhares, que aglutinados, possibilitam caminhos para a produção de novas situações e apreensões cênicas. Jatahy comunga com Lessa, Thomas e Forjaz a instauração de uma poética de encenação híbrida, formam uma geração de diretoras engajadas com o rigor técnico visual e estético, sem perder de vista uma relação sensível com o espectador e com as questões do presente.

\section{Futuro da encenação feminista}

O desejo pelo reconhecimento das diretoras do passado e do presente e a necessidade de abertura de espaços profissionais para futuras artistas da cena: são alguns dos propósitos deste breve texto, que rastreou lugares de resistências e o resgate de memórias femininas. Sem pontos finais, mas com inúmeras reticências, deixamos aqui um registro de nossas inquietações, que continuam reverberando nos futuros estudos sobre o teatro e a mulher. A força da prática artística feminista possibilita ampliar os limites das nossas reflexões. Resistir culturalmente com criatividade exige coragem para questionar os discursos dominantes e estruturas de poder masculinizados. $O$ fazer artístico das diretoras aqui analisadas, força-nos a sair dos nossos enquadramentos habituais. Pretendemos finalmente com este artigo suscitar novas e urgentes discussões em torno do papel da mulher como encenadora brasileira, e investigar suas 
práticas e pensamentos teatrais. Sabemos que este breve recorte sobre o assunto, excluem tantas outras diretoras. O próximo passo é o rastreamento das diretoras de outras regiões do país, como o Sul, Centro-Oeste, Norte e Nordeste, como formas de legar visibilidades e empoderamentos, descentralizadas do eixo Rio-São Paulo. Deste modo, trouxemos à tona mulheres de várias épocas, que ousaram e ainda ousam hoje e que anseiam alargar suas obras e seus experimentos cênicos para além da consciência de si mesmas. Diretoras que buscam sempre romper barreiras estéticas e ideológicas. Finalizamos esta exposição, defendendo que o lugar da criação teatral feminina é este campo em expansão, e que a autenticidade da artista da cena se faz sempre em diálogo, em trânsito, em construção, como a própria ideia de identidade da mulher, sempre em movimento fluído e em busca de mutações. O futuro feminino no teatro é agora.

\section{Referências}

ANDRADE, Ana Lúcia Vieira de; EDELWEISS, Ana Maria de B. Carvalho (org.). A mulher e o teatro brasileiro do século XX. São Paulo: Editora Hucitec; Brasília: Capes, 2008.

BUTLER, Judith. Problemas de gênero: feminismo e subversão de identidade. Tradução de Renato Aguiar. Rio de Janeiro: Civilização Brasileira, 2010.

CARVALHO, Marcelo Braga. Myrian Muniz: uma pedagoga do teatro. São Paulo, 2011. Dissertação (mestrado) - Programa de Pós-Graduação em Artes, Universidade Estadual Paulista.

COSTA, José da. Uma teia sobre o cotidiano: entrevista com Christiane Jatahy. Revista sala preta. São Paulo: Programa de Pós-Graduação em Artes Cênicas da ECA/USP, vol. 15, n. 2, p. 211-230, 2015.

DELGADO, Maria M., HERITAGE, Paul. Diálogos no palco: 26 diretores falam de teatro. Rio de Janeiro: Ed. Francisco Alves, 1999.

FERNANDES, Sílvia. Teatralidades Contemporâneas. São Paulo, Perspectiva, 2009. GUZIK, Alberto. 'Bonde' faz do público testemunha da violência. O Estado de S. Paulo, São Paulo, 8 mar. 2002. Caderno 2.

JATAHY, Christiane. Fronteira e instabilidade. 2010. Disponível em: <<http://tempofestival.com.br/simultaneo/fronteira-e-instabilidade/>. Acesso em: 20 out. 2018.

MONEY, John; EHRHARDT, Anke. Man and woman, boy and girl. New York: New American Library, 1974.

MOSTAÇO, Edelcio. Considerações sobre História do teatro brasileiro. Revista sala preta. São Paulo: Programa de Pós-Graduação em Artes Cênicas da ECA/USP. vol. 15, n. 2, p. 249-264, 2015. 
PAVIS, Patrice. A Encenação Contemporânea: origens, tendências, perspectivas. Trad. Nanci Fernandes. São Paulo: Perspectiva, 2010.

PRADO, Décio de Almeida. O teatro brasileiro moderno. 1aㅡ reimp. 3a ed. São Paulo: Perspectiva, 2008.

ROUBINE, Jean-Jacques. A linguagem da encenação teatral. Rio de Janeiro: Jorge Zahar Editor, 1998.

SANTOS, Maria Thais Lima. Na Cena do Dr. Dapertutto: Poética e Pedagogia em V. E. Meierhold. São Paulo: Perspectiva, 2010.

Recebido em: 28/09/2018 Aprovado em: 21/10/2018 